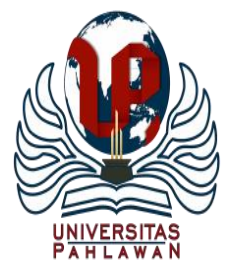

Edukatif : Jurnal Ilmu Pendidikan Volume 3 Nomor 2 Tahun 2021 Halm 385-395

EDUKATIF: JURNAL ILMU PENDIDIKAN

Research \& Learning in Education

https:/ledukatif.org/index.php/edukatif/index

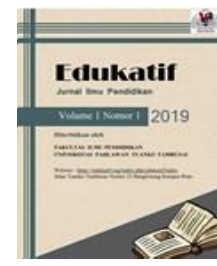

\title{
Meta Analisis Efektivitas Model Problem Based Learning dan Problem Solving Terhadap Kemampuan Berpikir Kritis Mata Pelajaran Matematika Siswa Sekolah Dasar
}

\author{
Tika Evi $^{1 凶}$, Endang Indarini ${ }^{2}$ \\ PGSD, FKIP, Universitas Kristen Satya Wacana, Jawa Tengah, Indonesia ${ }^{1,2}$ \\ E-mail : tikaevi09@ gmail.com¹, endang.indarini@uksw.edu²
}

\begin{abstract}
Abstrak
Dalam kurikulum 2013 seorang guru berkedudukan sebagai fasilitator dan membimbing siswa selama proses kegiatan belajar berlangsung, seharusnya seorang guru dapat memilih pendekatan atau model pembelajaran yang tepat agar proses pembelajaran dapat berjalan sesuai yang diharapkan serta dapat meningkatan berpikir kritis siswa. Tujuan dari penelitian ini yaitu untuk mengetahui komparasi model pembelajaran Problem Based Learning dan Problem Solving terhadap kemampuan berpikir kritis matematika siswa. Jenis penelitian yang digunakan dalam penelitian ini adalah penelitian Meta Analisis. Hasil uji Effect Size menunjukkan bahwa model pembelajaran Problem Based Learning dan Problem Solving tergolong sangat besar dalam memberikan pegaruh terhadap kemampuan berpikir kritis matematika. Jika dilihat dari hasil uji Ancova model pembelajaran Problem Based Learning dengan nilai rata-rata yaitu sebesar 64,9173 dan nilai rata-rata model pembelajaran Problem Solving sebesar 68.6220. Sehingga bisa disimpulkan bahwa model pembelajaran Problem Solving lebih efektif jika dibandingkan dengan model Problem Based Learning yang ditinjau dari kemampuan berpikir kritis matematika siswa Sekolah Dasar.
\end{abstract}

Kata Kunci: Problem Based Learning, Problem Solving, Kemampuan Berpikir Kritis, Matematika.

\begin{abstract}
In the 2013 curriculum, a teacher acts as a facilitator who guides students during the learning process. A teacher should be able to choose the appropriate approach or learning model so that the learning process can run as expected and can improve students' critical thinking. The purpose of this study was to see the comparison of the Problem Based Learning and Problem Solving learning models toward students' critical thinking skills. The type of this research is Meta analysis research. The result of the Effect Size test shows that the Problem Based Learning and Problem Solving learning models are classified as very large in giving an influence on the ability to think critically in mathematics. If viewed from the Ancova test results, the Problem Based Learning learning model with an average value of 64.9173 and an average value of the Problem Solving learning model of 68.6220. So, it can be concluded that the Problem Solving learning model is more effective compared to the Problem Based Learning model in terms of elementary school students' mathematical thinking skills.
\end{abstract}

Keywords: Problem Based Learning, Problem Solving, Critical Thinking Skills, Mathematics.

Copyright (c) 2021 Tika Evi, Endang Indarini

$\triangle$ Corresponding author

Email : tikaevi09@gmail.com

DOI : https://doi.org/10.31004/edukatif.v3i2.314

ISSN 2656-8063 (Media Cetak)

ISSN 2656-8071 (Media Online)

Edukatif : Jurnal Ilmu Pendidikan Vol 3 No 2 Tahun 2021 p-ISSN 2656-8063 e-ISSN 2656-8071 


\section{PENDAHULUAN}

Selama proses kegiatan belajar berlangsung seorang guru tidak hanya berkedudukan sebagai fasilitator tetapi guru juga harus membimbing siswa. Seorang guru seharusnya dapat memilih pendekatan atau model pembelajaran yang sesuai, supaya proses pembelajaran dapat berlangsung dengan baik sesuai yang diharapkan serta dapat meningkatkan kemampuan berpikir kritis siswa. (Kowiyah, 2012) berpikir kritis adalah suatu kemampuan yang dimiliki oleh setiap orang, yang bisa diasah, diukur, ditingkatkan. Berpikir kritis adalah suatu keahlian yang wajib diperkenalkan pada siswa karena keahlian ini sangat dibutuhkan dalam kehidupan (Syahroni, 2016). Berpikir kritis itu sangat penting bagi siswa, seorang siswa bisa memahami kondisi suatu daerah dengan kendala yang ada, kendala ini bisa diselesaikan jika dalam proses berpikir kritis siswa mempunyai kesadaran dalam membuat, memandu, sera mengukur apa yang akan dipelajari. siswa yang mempunyai keahlian dalam berpikir kritis bisa mempertimbangkan sesuatu dengan biak sebelum mengambil keputusan untuk mengatasi suatu permasalahan yang ada di lingkungannya (Ati \& Setiawan, 2020). Matematika merupakan salah satu mata pelajaran yang bisa membangun pemikiran logis, terstrukur dan kreatif. Pelajaran matematika sudah ada semejak pendidikan dasar, pernyataan ini diperkuat dalam UU No. 20 Tahun 2003 tentang Sistem Pendidikan Nasional yang termuat di dalam Pasal 31 ayat 1 yang berbunyi matematika adalah mata pelajaran wajib diberikan pada setiap jenjang pendidikan. Permendikbud No 22 tahun 2016 tentang standar prooses bahwa Kurikulum 2013 menggunakan pendekatan saintifikasi yang menyarankan 3 model : (1) model pembelajaran berbasis penyingkapan/penelitian (discovery/inquiry learning), (2) model pembelajaran berbasis masalah (Problem Based Learning). (3) pembelajaran yang menghasilkan karya berbasis pemecahan masalah (Project Based Learning). Dengan demikian, penggunaan model dalam kegiatan pembelajaran sangat penting agar tujuan pembelajaran dapat tercapai.

Problem Based Learning adalah salah satu metode pembelajaran yang memakai masalah dunia nyata sebagai suatu lingkungan untuk siswa belajar berpikir kritis dan terampil dalam memecahkan suatu permasalahan sehingga mendapatkan pengetahuan dan konsep dari mata pelajaran (Aqib, 2013). Kelebihan Problem Based Learning menurut (Lestaringsih, 2017) Problem Based Learning memiliki kelebihan yang meliputi pemecahan masalah merupakan teknik yang baik untuk dapat lebih memahami pembelajaran, dapat menstimulus serta dapat memberi kepuasan untuk menemukan pengetahuan lain bagi siswa, membantu siswa untuk mengembangkan dan mempertanggungjawabkan pembelajaran yang mereka lakukan, pembelajaran menjadi lebih menyenangkan, dapat mendorong siswa untuk berpikir kritis dengan mengalami secara langsung pengetahuan atau permasalahan yang mereka dapat dalam dunia nyata. Langkah-langkah model Problem Based Learning, yaitu sebagai berikut: (1) orientasi peserta didik pada masalah, (2) mengorganisasikan peserta didik untuk belajar, (3) membimbing penyelidikan individu maupun kelompok, (4) mengembangkan dan menyajikan hasil karya, (5) menganalisis dan mengevaluasi proses pemecahan masalah.

Pembelajaran Problem Solving merupakan model pembelajaran yang bisa membantu siswa untuk mengawasi serta mendalami suatu permasalahan sebagai jalan keluar (Ariyanto, dkk. 2018). Menurut (Juliasnyah, dkk. 2012) Problem Solving adalah suatu metode penyelesaian suatu permasalahan dengan cara mengumpulkan data agar bisa menarik kesimpulan. Kelebihan dari Problem Based Learning (Yakin, dkk. 2013) yaitu sebagai berikut: 1) model menjadi lebih relevan dalam dunia pendidikan di sekolah, 2) membiasakan siswa ahli dalam pemecahan masalah yang dihadapi, 3) mendorong siswa untuk berpikir kreatif dan terampil dalam memecahkan masalah. Model Problem Based Learning dan model Problem Solving merupakan model pembelajaran yang berbasis masalah. Langkah-langkah model Problem Solving secara garis besar, yaitu sebagai berikut : (1) memahami masalah, (2) merencanakan penyelesaian, (3) melaksanakan penyelesaian, (4) mengecek kembali. 
Tujuan dilakukannya penelitian ini yaitu untuk mengetahui ada tidaknya perbedaan komparasi efektivitas model Problem Based Learning dan Problem Solving terhadap kemampuan berpikir kritis matematika siswa sekolah dasar. Penelitian ini dilakukan dengan cara mengumpulkan, meringkas dan menelaah dari penelitian terdahulu, penelitian seperti ini sudah pernah ditulis oleh peneliti sebelumnya hanya saja hasil yang didapatkan berbeda-beda, ada penelitian yang membuktikan bahwa model Problem Based Learning lebih efektif jika dibandingkan dengan Problem Solving hal ini tidak sesuai dengan hasil penelitian ini, dikarenakan dalam hasil penelitian ini model Problem Solving lebih efektif jika dibandingkan dengan model Problem Based Learning.

\section{METODE PENELITIAN}

Penelitian ini menggunakan jenis penelitian Meta Analisis. Meta Analisis merupakan suatu ringkasan dari penelitian yang mengkaji hasil dari suatu penelitian secara statistik. Menurut (Alyakin, 2017) Meta Analisis adalah suatu penelitian yang dapat dibuat dengan cara mengumpulkan, meringkas, menelaah data penelitian yang sudah dialakukan oleh peneliti lain. Dalam penelitian ini data diperoleh dari artikel yang ada di jurnal online dengan menggunakan Google Cendekia dan Scholar. Dari hasil penelusuran didapatkan 20 artikel kemudian ditelaah. Populasi dalam penelitian ini adalah artikel ilmiah yang dipublikasikan. (1) artikel yang digunakan berjudul model pembelajaran Problem Based Learning dan model Problem Solving terhadap kemampuan berpikir kritis matematika, (2) penelitian ini dilakukan di jenjang Sekolah Dasar (SD), (3) artikel yang digunakan yaitu artikel terbitan 10 tahun terakhir yaitu 2011-2020, (4) cakupan penelitian ini adalah wilayah Indonesia. Dari hasil pencarian artikel diperoleh 10 sampel model pembelajaran Problem Based Learning dan 10 sampel model Problem Solving, pencarian ini bertujuan untuk menemukan jurnal yang memenuhi standar judul artikel, setiap model memperoleh 10 artikel yang sesuai dan kemudian ditelaah.

Instrumen penelitian merupakan salah satu digunakan untuk mengumpulkan data, dalam penelitian ini instrumen data yang dipakai adalah lembar pemberian kode, untuk menghimpun data dari hasil pengaruh model pembelajaran Problem Based Learning dan model Problem Solving ditinjau dari kemampuan berpikir kritis matematika siswa Sekolah Dasar. Cara analisis data yang digunakan dalam penelitian ini yaitu penghitungan Effect Size atau perhitungan besar pengaruh. Effect size merupakan suatu cara yang digunakkan agar dapat mengetahui besar pengaruh model pembelajaran. Pada statistika Effect Size digunakan untuk menentukan besar perbandingan keefektifan dalam penelitian. Pada penelitian ini data yang digunakan yakni hasil rata-rata pretest dan posstest pada artikel kemampuan berpikir kritis matematika yang sudah dianalisis.

\section{HASIL DAN PEMBAHASAN PENELITIAN}

Penelitian ini dilakukan agar dapat diketahui komparasi model pembelajaran Problem Based Learning dan Problem Solving terhadap kemampuan berpikir kritis matematika siswa. Analisis dua model pembelajaran dilakukan untuk menguji hipotesis. Penelitian ini menggunakan uji hipotesis, yang bertujuan agar dapat mengetaahui apakah hipotesis diterima atau ditolak. $\mathrm{H}_{\mathrm{o}}$ berarti bahwa tidak terdapat perbedaan yang signifikan dari kedua model Problem Based Learning dan Problem Solving dalam kemampuan berpikir kritis siswa kelas IV SD sedangkan $\mathrm{H}_{\mathrm{a}}$ berarti terdapat perbedaan yang signifikan dari kedua model Problem Based Learning dan Problem Solving dalam kemampuan berpikir kritis siswa kelas IV SD.

Hasil perhitungan dari hipotesis yang dilakukan melalui uji Ancova pada model pembelajaran dapat dilihat pada tabel 10, dengan nilai Sig. 0,003 yang artinya lebih kecil dari 0,05 $(0,003<0,005)$. Hasil dari uji Ancova adalah $\mathrm{f}$ hitung $>\mathrm{f}$ tabel yaitu 54,014 > 3,59 dan signifikasinya 0,003 $<0,05$ dan terbukti bahwa bahwa $\mathrm{H}_{\mathrm{o}}$ ditolak dan $\mathrm{H}_{\mathrm{a}}$ diterima. Jika dilihat dari hasil uji tersebut ada perbedaan secara signifikan pada model Problem Based Learning dan Problem Solving ditinjau dari kemampuan berpikir kritis matematika 
siswa Sekolah Dasar. Meskipun dua model pembelajaran ini dapat meningkatkan kemampuan berpikir kritis matematika, akan tetapi model pembelajaran Problem Solving lebih efektif jika dibandingkan dengan model Problem Based Learning. Untuk lebih lanjut dapat dilihat dalam tabel 9, nilai rata-rata model Problem Based Learning sebesar 64,9173, sedangkan untuk nilai rata-rata Problem Solving sebesar 68,6220. Jika dilihat dari nilai rata-rata yang diperoleh dari kedua model tersebut maka dapat disimpulkan bahwa Problem Solving lebih unggul jika dibandingkan dengan Problem Based Learning.

Setelah selesai uji hipotesis yang selanjutnya yaitu perhitungan Effect Size dengan model pembelajaran Problem Based Learning dan Problem Solving. Hasil perhitungan Effect Size dengan hasil 0,864 dengan nilai Sig. sebesar 0,003. Hal ini menunjukan bahwa model Problem Based Learning dan Problem Solving memberikan pengaruh sangat besar terhadap kemampuan berpikir kritis matematika.

Hasil dari penyeleksian beberapa artikel ditetapkan sampel sebanyak 20 artikel yang signifikan selanjutnya dianalisis untuk menentukan hasil penelitian, yang diperlukan adalah skor rata-rata pretest dan posstest pada model Problem Based Learning dan Problem Solving pada peningkatan kemampuan berpikir kritis matematika. Dibawah ini merupakan hasil dari pretest dan posstest yang diperoleh, yaitu :

Tabel 1

Persentase Peningkatan Kemampuan Berpikir Kritis Matematika

\begin{tabular}{|c|c|c|c|c|}
\hline \multirow{2}{*}{ No } & Kode & \multicolumn{3}{|c|}{ Persentase (\%) } \\
\cline { 3 - 5 } & \multirow{2}{*}{ Data } & $\begin{array}{c}\text { Skor } \\
\text { Pretest }\end{array}$ & $\begin{array}{c}\text { Skor } \\
\text { Posttest }\end{array}$ & $\begin{array}{c}\text { Peningkata } \\
\text { n }\end{array}$ \\
\hline 1 & $1 \mathrm{P}$ & 51,93 & 82,09 & 30,16 \\
\hline 2 & $2 \mathrm{P}$ & 65,677 & 68,094 & 2,417 \\
\hline 3 & $3 \mathrm{P}$ & 11,6 & 14,17 & 2,57 \\
\hline 4 & $4 \mathrm{P}$ & 62,92 & 72,08 & 9,16 \\
\hline 5 & $5 \mathrm{P}$ & 67 & 83,5 & 16,5 \\
\hline 6 & $6 \mathrm{P}$ & 58,82 & 84,84 & 26,02 \\
\hline 7 & $7 \mathrm{P}$ & 66,7 & 91,51 & 24,81 \\
\hline 8 & $8 \mathrm{P}$ & 67,61 & 69,03 & 1,42 \\
\hline 9 & $9 \mathrm{P}$ & 62,78 & 53,68 & 9,1 \\
\hline 10 & $10 \mathrm{P}$ & 59,96 & 83,52 & 23,56 \\
\hline & Rerata & 57,49 & 70,25 & 14,57 \\
\hline
\end{tabular}

Pada tabel 1 bisa dilihat presentase rata-rata peningkatan kemampuan berpikir kritis matematika dengan menggunakan model Problem Based Learning dari skor terendah 1,42\% sedangkan paling tinggi yaitu sebanyak $30,16 \%$ dan rata-ratanya sebesar $14,56 \%$. Persentase rata-rata kemampuan berpikir kritis matematika sebelum menggunakan model Problem Based Learning sebesar 57,49\%. Sedangkan persentase rata-rata kemampuan berpikir kritis matematika setelah menerapkan model Problem Based Learning sebesar 70, 25\%. Persentase sebelum dan setelah menerapkan model Problem Based Learnig meningkat sekitar 14, $57 \%$. 
Tabel 2

Persentase Peningkatan Kemampuan Berpikir Kritis Matematika

\begin{tabular}{|c|c|c|c|c|}
\hline \multirow{2}{*}{ No } & \multirow{2}{*}{$\begin{array}{c}\text { Kode } \\
\text { Data }\end{array}$} & \multicolumn{3}{|c|}{ Persentase (\%) } \\
\cline { 3 - 5 } & & $\begin{array}{c}\text { Skor } \\
\text { Pretest }\end{array}$ & $\begin{array}{c}\text { Skor } \\
\text { Posttest }\end{array}$ & Peningkatan \\
\hline 1 & $1 \mathrm{~S}$ & 82 & 92 & 10 \\
\hline 2 & $2 \mathrm{~S}$ & 61,32 & 66,85 & 5,53 \\
\hline 3 & $3 \mathrm{~S}$ & 60,36 & 75,6 & 15,24 \\
\hline 4 & $4 \mathrm{~S}$ & 61,87 & 76,04 & 14,17 \\
\hline 5 & $5 \mathrm{~S}$ & 37,35 & 54,74 & 17,39 \\
\hline 6 & $6 \mathrm{~S}$ & 72,882 & 86,114 & 13,232 \\
\hline 7 & $7 \mathrm{~S}$ & 68,64 & 78,75 & 10,11 \\
\hline 8 & $8 \mathrm{~S}$ & 18,967 & 21,687 & 2,72 \\
\hline 9 & $9 \mathrm{~S}$ & 75,1 & 83,26 & 8,16 \\
\hline 10 & $10 \mathrm{~S}$ & 72,55 & 85,35 & 12,8 \\
\hline \multicolumn{2}{|c|}{ Rerata } & 61,10 & 72,03 & 10,93 \\
\hline
\end{tabular}

Pada tabel bisa dilihat bahwa Persentase rata-rata pada peningkatan kemampuan berpikir kritis matematika menggunakan model pembelajaran Problem Solving dari skor terendah 2,72\% sedangkan skor paling tinggi $17,39 \%$ dan rata-ratanya $10,93 \%$. Persentase rata-rata kemampuan berpikir kritis matematika sebelum menggunakan model pembelajaran Problem Solving 61,10\%. Sedangkan persentase rata-rata kemampuan berpikir kritis matematika setelah menggunakan model pembelajaran Problem Solving sebesar 72,03\%. Presentase rata-ratanya dengan menerapkan Problem Solving meningkat sebanyak 10, 93\%.

Tabel 3

Komparasi Hasil Pengukuran Kemampuan Berpikir Kritis

\begin{tabular}{cccc}
\hline Pengukuran & \multicolumn{2}{c}{$\begin{array}{c}\text { Rata-Rata Skor } \\
\text { (Mean) }\end{array}$} & Selisih \\
\cline { 2 - 3 } & PBL & PS & \\
\hline Pretest & $57.50 \%$ & $61.10 \%$ & $3.60 \%$ \\
\hline Posttest & $70.30 \%$ & $72.34 \%$ & $2.04 \%$ \\
\hline
\end{tabular}

Pada tabel 3 diatas terlihat bahwa skor rata-rata Pretest dari kedua model dengan selisih sebesar 3,60\%. Sedangkan untuk selisih skor rata-rata pada Posttest antara model Problem Based Learning dan Problem Solving 2,04\%. Berikut ini adalah diagram komparasi antara model Problem Based Learning dan Problem Solving yang disajikan dalam bentuk diagram. 
390 Meta Analisis Efektivitas Model Problem Based Learning dan Problem Solving Terhadap Kemampuan Berpikir Kritis Mata Pelajaran Matematika Siswa Sekolah Dasar - Tika Evi, Endang Indarini

DOI : https://doi.org/10.31004/edukatif.v3i2.314

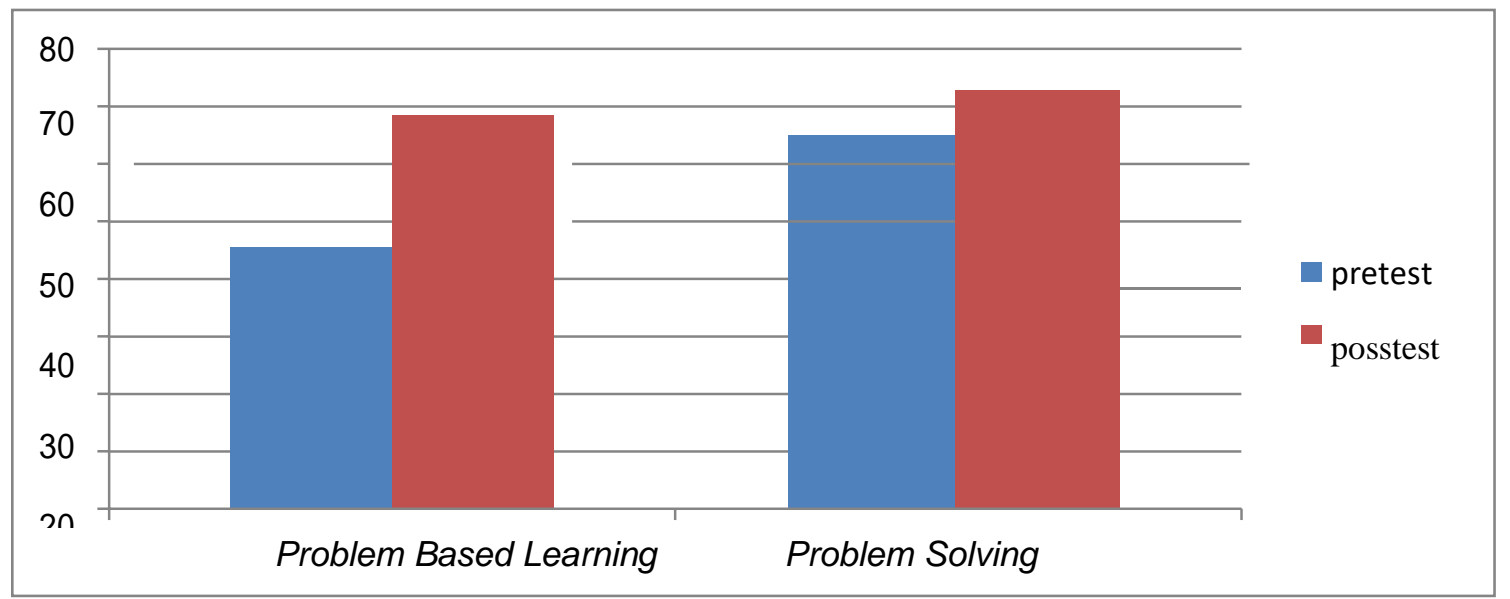

Diagram 1. Komparasi Data Antara Model Pembelajaran Problem Based Learning dan Problem Solving

Dari diagram diatas, bisa disimpulkan adanya peningkatan dari skor pretest dan posstest pada model Problem Based Learning dan Problem Solving.

Tabel 4

Uji Normalitas Model Pembelajaran Problem Based Learning dan Problem Solving

\begin{tabular}{|c|c|c|c|c|c|c|c|}
\hline & \multirow[t]{2}{*}{ KELAS } & \multicolumn{3}{|c|}{ Kolmogorov-Smirnov ${ }^{\mathrm{a}}$} & \multicolumn{3}{|c|}{ Shapiro-Wilk } \\
\hline & & Statistic & Df & Sig. & Statistic & Df & Sig. \\
\hline \multirow{4}{*}{$\begin{array}{l}\text { KEMAMPUAN } \\
\text { BERPIKIR } \\
\text { KRITIS }\end{array}$} & PRETEST MODEL PBL & .203 & 10 & $.200^{*}$ & .857 & 10 & .070 \\
\hline & POSTEST MODEL PBL & .213 & 10 & $.200^{*}$ & .866 & 10 & .089 \\
\hline & PRETEST MODEL PS & .267 & 10 & .041 & .867 & 10 & .093 \\
\hline & POSTEST MODEL PS & .250 & 10 & .076 & .853 & 10 & .064 \\
\hline
\end{tabular}

*. This is a lower bound of the true significance.

a. Lilliefors Significance Correction

Hasil uji normalitas pretest dan posstest dengan model Problem Based Learning dan Problem Solving dapat dilihat pada tabel 4 diatas. Uji normalitas data dengan Shapiro-Wilk dengan memakai SPSS 20.0 for windows, memperoleh nilai signifikan $>0,05$ dengan demikian data ini tergolong berdistribusi normal. Tingkat signifikasi skor pretest model Problem Based Learning adalah 0,070>0,05 artinya berdistribusi normal. (1) tingkat signifikasi skor posstest model pembelajaran Problem Based Learning adalah 0,089 >0,05 artinya berdistribusi normal. (2) tingkat signifikasi skor pretest model pembelajaran Problem Solving adalah $0,093>0,05$ artinya berdistribusi normal. (3) tingkat signifikasi skor posstest model pembelajaran Problem Solving adalah $0,064>0,05$ artinya berdistribusi normal.

Tabel 5

Uji Homogenitas Skor Pretest Model Problem Based Learning dan Problem Solving

\begin{tabular}{|ll|c|c|c|c|}
\hline & & $\begin{array}{c}\text { Levene } \\
\text { Statistic }\end{array}$ & $\mathrm{df1}$ & $\mathrm{df2}$ & Sig. \\
\hline KEMAMPUAN & Based on Mean & .276 & 1 & 18 & .606 \\
BERPIKIR & Based on Median & .506 & 1 & 18 & .486 \\
KRITIS & $\begin{array}{l}\text { Based on Median and with } \\
\text { adjusted df }\end{array}$ & .506 & 1 & $\begin{array}{c}17.83 \\
7\end{array}$ & .486 \\
\hline
\end{tabular}

Edukatif : Jurnal Ilmu Pendidikan Vol 3 No 2 Tahun 2021 p-ISSN 2656-8063 e-ISSN 2656-8071 
391 Meta Analisis Efektivitas Model Problem Based Learning dan Problem Solving Terhadap Kemampuan Berpikir Kritis Mata Pelajaran Matematika Siswa Sekolah Dasar - Tika Evi, Endang Indarini

DOI : : https://doi.org/10.31004/edukatif.v3i2.314

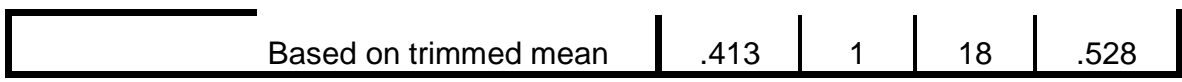

Tabel 5 diatas menunjukan hasil uji homogenitas dengan skor pretest dengan metode Leven's Test melihat rata-rata (Based on Mean). Nilai homogenitas dilihat dari nilai signifikasi sebesar $0,606>0,05$ sehingga data tersebut variansi homogen.

Tabel 6

Uji Homogenitas Skor Posttest Model Pembelajaran Problem Based Learning dan Problem Solving

\begin{tabular}{|ll|r|r|r|r|}
\hline & & Levene Statistic & df1 & \multicolumn{1}{c|}{ df2 } & \multicolumn{1}{c|}{ Sig. } \\
\hline & Based on Mean & .025 & 1 & 18 & .877 \\
KEMAMPUAN BERPIKIR & Based on Median & .075 & 1 & 18 & .788 \\
KRITIS & $\begin{array}{l}\text { Based on Median and with } \\
\text { adjusted df }\end{array}$ & .075 & 1 & 17.825 & .788 \\
& Based on trimmed mean & .039 & 1 & 18 & .846 \\
\hline
\end{tabular}

Tabel 6 diatas menunjukan hasil uji homogenitas skor posttest Model Pembelajaran Problem Based Learning dan Problem Solving dengan metode Levene's Test dengan rata-rata (Based on Mean) nilai signifikasi 0,877>0,05 sehingga data tersebut variansi homogen.

Tabel 7

Uji Lineritas Skor Pretest dan Posttest Model Pembelajaran Problem Based Learning

\begin{tabular}{|c|c|c|c|c|c|c|c|}
\hline \multicolumn{8}{|c|}{ ANOVA Table } \\
\hline & & & $\begin{array}{l}\text { Sum of } \\
\text { Squares }\end{array}$ & Df & $\begin{array}{l}\text { Mean } \\
\text { Square }\end{array}$ & $\mathrm{F}$ & Sig. \\
\hline \multirow{7}{*}{$\begin{array}{l}\text { POSTEST * } \\
\text { PRETEST }\end{array}$} & \multirow{5}{*}{ Between Groups } & (Combined) & 1340.461 & 7 & 191.494 & 3.689 & .230 \\
\hline & & Linearity & 306.763 & 1 & 306.763 & 5.909 & .136 \\
\hline & & Deviation & & & & & \\
\hline & & from & 1033.698 & 6 & 172.283 & 3.319 & .250 \\
\hline & & Linearity & & & & & \\
\hline & Within Groups & & 103.824 & 2 & 51.912 & & \\
\hline & Total & & 1444.285 & 9 & & & \\
\hline
\end{tabular}

Dari tabel 7 diatas dapat dilihat hasil uji linearitas skor pretest dan posttest dengan model Problem Based Learning dengan menggunakan Deviation from Linearity dengan nilai signifikasi sebesar 0,250>0,05 sehingga dapat disimpulkan bahwa data diatas mempunyai yang linear.

Tabel 8

Uji Lineritas Skor Pretest dan Posttest Model Pembelajaran Problem Solving

ANOVA Table

\begin{tabular}{|lll|c|c|c|c|c|}
\hline & & & Sum of & Df & Mean & F & Sig. \\
& & Squares & & Square & & \\
\hline \multirow{2}{*}{ POSTEST * PRETEST } & Between & (Combined) & 2225.727 & 7 & 317.961 & .430 & .832 \\
& Groups & Linearity & 1250.817 & 1 & 1250.817 & 1.692 & .323
\end{tabular}


392 Meta Analisis Efektivitas Model Problem Based Learning dan Problem Solving Terhadap Kemampuan Berpikir Kritis Mata Pelajaran Matematika Siswa Sekolah Dasar - Tika Evi, Endang Indarini

DOI : : https://doi.org/10.31004/edukatif.v3i2.314

\begin{tabular}{|l|l|l|l|l|l|}
\hline \multicolumn{1}{c|}{$\begin{array}{c}\text { Deviation from } \\
\text { Linearity }\end{array}$} & 974.911 & 6 & 162.485 & .220 & .937 \\
Within Groups & 1478.708 & 2 & 739.354 & & \\
Total & 3704.435 & 9 & & & \\
\hline
\end{tabular}

Dari tabel 8 dapat dilihat hasil uji linearitas skor Pretest dan Posttest Model Pembelajaran Problem Solving dengan menggunakan Deviation from Linearity dengan nilai signifikasi 0,937 > 0,05 oleh karena itu skor pretest dan posttest pada model pembelajaran Problem Solving mempunyai hubungan yang linear.

\section{Tabel 9}

\section{Hasil Analisis Data Menggunakan Uji Ancova}

\section{Descriptive Statistics ${ }^{a}$}

Dependent Variable: POSTEST

\begin{tabular}{|c|c|c|c|}
\hline MODEL_PEM & Mean & Std. Deviation & N \\
\hline MODEL PBL & 64.9173 & 53.36889 & 10 \\
MODEL PS & 68.6220 & 47.84221 & 10 \\
Total & 66.8201 & 49.46917 & 20 \\
\hline
\end{tabular}

Hasil analisis data menggunakan uji Ancova dengan model Problem Based Learning memiliki 10 artikel dengan rata-rata 64,9173. Sedangkan model pembelajaran Problem Solving memiliki 10 artikel dengan ratarata 68, 6220. Hasil model Problem Solving lebih efektif ketika dibandingkan dengan model Problem Based Learning. Hasil ini didukung oleh penelitian dilakukan oleh Hendriana Monalisa yang berjudul "Komparasi Model Pembelajaran Problem Based Learning Dan Problem Solving Ditinjau Dari Pengaruh Terhadap Pencapaian Kemampuan Berpikir Kritis Pada Siswa Kelas V" dengan hasil uji Ancova yang dilaksanakan menggunakan model pembelajaran Problem Based Learning dengan rata-rata 75,1154 sedangkan dengan model Problem Solving dengan rata-rata 84,6724. Hasil dengan model Problem Solving lebih efektif dibandingkan dengan model Problem Based Learning.

Tabel 10

Hasil Analisis Uji Ancova

\begin{tabular}{|l|c|c|c|c|c|c|}
\hline Dependent Variable: POSTEST & $\begin{array}{c}\text { Type III } \\
\text { Sum of } \\
\text { Squares }\end{array}$ & Df & $\begin{array}{c}\text { Mean } \\
\text { Square }\end{array}$ & F & Sig. & $\begin{array}{c}\text { Partial Eta } \\
\text { Squared }\end{array}$ \\
\hline Corrected & $40174.665^{\mathrm{b}}$ & 2 & 20087.332 & 54.014 & .000 & .864 \\
Model & 298.605 & 1 & 298.605 & .803 & .383 & .045 \\
Intercept & 39911.921 & 1 & 39911.921 & 107.322 & .000 & .863 \\
PRETEST & 37.175 & 1 & 37.175 & .100 & .003 & .006 \\
MODEL_PEM & 6322.117 & 17 & 371.889 & & & \\
Error & 388659.850 & 20 & & & & \\
Total & 46496.782 & 19 & & & \\
Corrected Total & & & & \\
\hline
\end{tabular}

a. R Squared $=.864$ (Adjusted R Squared $=.848)$ 
Hasil uji Ancova yang terdapat pada kolom model pembelajaran tersebut dapat disimpulkan bahwa signifikan dalam kolom Sig. sebesar 0,003. $\mathrm{F}$ hitung yang diperoleh adalah 54,014 dan $\mathrm{F}$ tabel yang terdapat dari hasil data diatas adalah 3,59. 3,59 didapatkan menggunakan rumus df2=n-k,df2=10-(2+1), df2=10-3,df2=7. Untuk menemukan hasil 3,59 terdapat pada $\mathrm{F}$ tabel yang disesuaikan berdasarkan jumlah sampel dikurangi jumlah variabel (bebas dan terikat), sehingga ditemukan hasil 3,59.

Penggunaan model pembelajaran Problem Based Learning dan Problem Solving juga mempunyai besar pengaruh terhadap peningkatan kemampuan berpikir matematika hal tersebut bisa diketahui dengan uji Effect Size. Berikut ini adalah Effect Size.

Tabel 11

Interpretasi Effect Size

\begin{tabular}{|c|c|}
\hline Effect Size & Interpretasi \\
\hline $0<\mathrm{d}<0,2$ & Kecil \\
\hline $0,2<\mathrm{d} \leq$ & Sedang \\
\hline $0,5<\mathrm{d} \leq 0,8$ & Besar \\
\hline $\mathrm{d}>0,8$ & Sangat Besar \\
\hline
\end{tabular}

Dibawah ini merupakan hasil analisis Effect Size untuk mengetahui perbedaan model Problem Based Learning dan Problem Solving.

Tabel 12

Uji Effect Size Menggunakan Uji Ancova

Dependent Variable: POSTEST
\begin{tabular}{|l|c|c|c|c|c|c|}
\hline Source & $\begin{array}{c}\text { Type III Sum } \\
\text { of Squares }\end{array}$ & Df & $\begin{array}{c}\text { Mean } \\
\text { Squares }\end{array}$ & $F$ & Sig. & $\begin{array}{c}\text { Patrial Eta } \\
\text { Squared }\end{array}$ \\
\hline Corrected Model & $40174.665^{\mathrm{b}}$ & 2 & 20087.332 & 54.014 & .003 & .864 \\
Intercept & 298.605 & 1 & 298.605 & .803 & .383 & .045 \\
PRETEST & 39911.921 & 1 & 39911.921 & 107.322 & .000 & .863 \\
MODEL_PEM & 37.175 & 1 & 37.175 & .100 & .756 & .006 \\
Error & 6322.117 & 17 & 371.889 & & & \\
Total & 388659.850 & 20 & & & & \\
Corrected Total & 46496.782 & 19 & & & & \\
\hline
\end{tabular}

a. $R$ Squared $=.864$ (Adjusted R Squared $=.848)$

Hasil uji Effect Size menggunakan uji Ancova menggunakan model pembelajaran Problem Based Learning dan Problem Solving terdapat hasil yang terlihat pada kolom Corrected Model yang diketahui Partial Eta Squared sebesar 0,864 dengan nilai Sig. sebesar 0,003. Hasil tersebut menunjukkan bahwa model Problem Based Learning dan Problem Solving tergolong sangat besar dalam memberikan pengaruh terhadap kemampuan berpikir kritis matematika.

Penelitian ini dapat mendukung teori tentang Problem Based Learning dan Problem Solving yang ditinjau dari kemampuan berpikir kritis matematika terhadap penelitian melalui meta analisis, peneliti juga memberi saran agar guru dapat mengembangkan kreativitas cara mengajar secara lebih menarik dengan 
394 Meta Analisis Efektivitas Model Problem Based Learning dan Problem Solving Terhadap Kemampuan Berpikir Kritis Mata Pelajaran Matematika Siswa Sekolah Dasar - Tika Evi, Endang Indarini

DOI : : https://doi.org/10.31004/edukatif.v3i2.314

menggunakan model pembelajaran Problem Solving terutama untuk meningkatkan kemampuan berpikir kritis pada mata pelajaran matematika. Serta dapat menjadi sumber informasi bagi peneliti selanjutnya untuk melakukan pengkajian pengaruh model pembelajaran Problem Based Learning dan model Problem Solving pada kemampuan berpikir kritis siswa diwaktu mendatang terkait dengan keefektifan model pembelajaran Problem Based Learning dan model Problem Solving. Penelitian ini telah diusahakan sesuai dengan prosedur ilmiah, namun demikian masih memiliki keterbatasan, yaitu : (1) peneliti hanya membahas dua variabel (2) jumlah sampel hanya memenuhi jumlah minimum yaitu hanya 20 sampel / artikel.

\section{KESIMPULAN}

Tujuan dari penelitian ini yaitu dengan menggunakan meta analisis untuk mengetahui ada tidaknya perbedaan komparasi efektivitas model Problem Based Learning dan Problem Solving terhadap kemampuan berpikir kritis matematika dari penelitian eksperimen yang telah dipublikasikan. Kemampuan berpikir kritis pada pembelajaran matematika dengan model pembelajaran Problem Solving lebih efektif dibadingkan dengan menggunakan model Problem Based Learning. Problem Based Learning dan Problem Solving dapat meningkatkan keterampilan berpikir kritis pada tingkat yang sedikit berbeda. Model pembelajaran Problem Solving dapat meningkatkan keterampilan berpikir kritis dengan kadar yang sedikit berbeda. Model Problem Based Learning dapat meningkatkan keterampilan berpikir kritis sebesar 64,9173, sedangkan model pembelajaran Problem Solving dapat meningkatkan keterampilan berpikir kritis sebesar 68,6220 yang berarti terdapat perbedaan antara kedua model tersebut karena hasil Problem Solving lebih efektif daripada model Problem Based Learning. Berdasarkan perhitungan Effect Size diketahui Partial Eta Squared sebesar 0,864 dan nilai Sig. sebesar 0,003. Dari hasil ini, terlihat bahwa model Problem Based Learning dan Problem Solving dapat meningkatkan keterampilan berpikir kritis, dan tergolong sangat besar dalam hal mempengaruhi keterampilan berpikir kritis siswa matematika siswa Sekolah Dasar. Penelitian ini dilakukan untuk mendukung penelitian terdahulu tentang Efektivitas model Problem Based Learning dan Problem Solving terhadap kemampuan berpikir kritis siswa, peneliti menemukan konsep baru yang dimana Problem Solving lebih efektif jika dibandingkan dengan Problem Based Learning.

\section{DAFTAR PUSTAKA}

Afifah, E. P., Wahyudi, W., \& Setiawan, Y. (2019). Efektivitas Problem Based Learning dan Problem Solving Terhadap Kemampuan Berpikir Kritis Siswa Kelas V dalam Pembelajaran Matematika. MUST: Journal of Mathematics Education, Science and Technology, 4(1), 95. https://doi.org/10.30651/must.v4i1.2822.

Alyakin, D. R. (2017). Suatu Pendekatan Konseptual. Yogyakarta. CV. Budi Utama.

Aqib, Z. (2013). Model-model Media dan Strategi Pembelajaran Kontekstual (Inovatif). Bandung: Yrama Widya.

Ariyanto, M., Kristin, F., \& Anugraheni, I. (2018). Penerapan Model Pembelajaran Problem Solving untuk Meningkatkan Kemampuan Berpikir Kritis dan Hasil Belajar Siswa. JGK (Jurnal Guru Kita), 2(3), 106115. https://doi.org/10.24114/JGK.V2I3.10392.

Ati, T. P., \& Setiawan, Y. (2020). Efektivitas Problem Based Learning-Problem Solving Terhadap Kemampuan Berpikir Kritis dalam Pembelajaran Matematika Siswa Kelas V. Jurnal Cendekia : Jurnal Pendidikan Matematika, 4(1), 294-303. https://doi.org/10.31004/cendekia.v4i1.209.

Cahaya Phasa, K. (2021). Meta Analisis Pengaruh Model Pembelajaran Problem Based Learning Terhadap Kemampuan Berpikir Kritis dalam Pembelajaran Matematika. J-Cup.Org. Retrieved March 26, 2021, from https://www.j-cup.org/index.php/cendekia/article/view/296

Depdiknas. (2016) Undang-undang 22 tahun 2016 tentang Standar Proses Pendidikan Dasar dan Menengah. 
395 Meta Analisis Efektivitas Model Problem Based Learning dan Problem Solving Terhadap Kemampuan Berpikir Kritis Mata Pelajaran Matematika Siswa Sekolah Dasar - Tika Evi, Endang Indarini

DOI : https://doi.org/10.31004/edukatif.v3i2.314

Jakarta. Depdiknas.

Elektro, A. Y.-J. P. T. (2013). Pengaruh Metode Pembelajaran Problem Solving Terhadap Hasil Belajar Siswa Pada Standar Kompetensi Dasar-Dasar Kelistrikan di SMK Negeri 1 Jetis Mojokerto. In jurnalmahasiswa.unesa.ac.id. Retrieved March 23, 2021, from https://jurnalmahasiswa.unesa.ac.id/index.php/jurnal-pendidikan-teknik-elektro/article/view/1363.

Febriana, T., \& Indarini, E. (2020). Komparasi Pembelajaran Problem Based Learning (PBL) dan Problem Solving terhadap Kemampuan Berpikir Kritis Matematis Siswa Sekolah Dasar. Jurnal Basicedu, 4(4), 1016-1020. https://doi.org/10.31004/basicedu.v4i4.494.

Juliasnyah, W. A., Suryani, N., \& Agung, L. (2012). TEKNODIKA Matematika dalam Multimedia Flipbook: Kreatifitas Guru dalam Pengembangan Media Pembelajaran dalam Meningkatkan Minat Siswa. In jurnal.uns.ac.id. Retrieved March 23, 2021, from http://jurnal.fkip.uns.ac.id/teknodika.

Kowiyah. (2012). Kemampuan Berpikir Kritis. Jurnal Pendidikan Dasar, 3(5), 175-179.

Lestaringsih, E. D. (2017). Pengembangan Model Problem Based Learning dan Blended Learning dalam Pembelajaran Pemantapan Kemampuan Profesional Mahasiswa. In publikasi.dinus.ac.id. Retrieved March 23, 2021, from http://publikasi.dinus.ac.id/index.php/lite/article/view/1714

Monalisa, H., Harjono. (2020). Komparasi Model Pembelajaran Problem Based Learning dan Problem Solving Ditinjau dari Pengaruhnya Terhadap Pencapaian Kemampuan Berpikir Kritis Pada Mapel IPA Siswa Sd Kelas V. In PIONIR: Jurnal Pendidikan (Vol. 9, Issue 2). https://doi.org/10.22373/pjp.v9i2.8322

Supriadi, A. (2012). Meningkatkan Kemampuan Berpikir Kritis Dan Komunikasi Matematis Siswa Sekolah Menengah Pertama Melalui Pendekatan Inkuiri Terbimbing. http://repository.upi.edu

Syahroni. (2016). Pengaruh Model Problem Based Learning (PBL) Terhadap Pemahaman Konsep dan Keterampilan Berpikir Kritis Sisa Kelas IV Jambu Hilir Baluti 2 Pada Mata Pelajaran Ilmu Pengrtahuan Alam. Jurnal Pendidikan, 1(1), 65-71. 